Please do not remove this page

RMIT

UNIVERSITY

\title{
4 dimensional trajectory functionalities for air traffic management systems
}

Gardi, Alessandro Giacomo Maria; Sabatini, Roberto; Kistan, Trevor; Lim, Yixiang; Ramasamy, Subramanian

https://researchrepository.rmit.edu.au/esploro/outputs/9921862811401341/filesAndLinks?institution=61RMIT_INST\&index=null

Gardi, A. G. M., Sabatini, R., Kistan, T., Lim, Y., \& Ramasamy, S. (2015). 4 dimensional trajectory functionalities for air traffic management systems. Proceedings of the 2015 IEEE Integrated Communication, Navigation, and Surveillance Conference (ICNS 2015), 1-11.

https://doi.org/10.1109/ICNSURV.2015.7121246

Document Version: Accepted Manuscript

Published Version: https://doi.org/10.1109/ICNSURV.2015.7121246

Repository homepage: https://researchrepository.rmit.edu.au (C) 2015 IEEE

Downloaded On 2023/04/26 17:29:37 +1000

Please do not remove this page 
Thank you for downloading this document from the RMIT Research Repository.

The RMIT Research Repository is an open access database showcasing the research outputs of RMIT University researchers.

RMIT Research Repository: http://researchbank.rmit.edu.au/

\section{Citation:}

Gardi, A, Sabatini, R, Kistan, T, Lim, Y and Ramasamy, S 2015, '4 dimensional trajectory functionalities for air traffic management systems', in Proceedings of the 2015 IEEE Integrated Communication, Navigation, and Surveillance Conference (ICNS 2015), United States, 21-23 April 2015, pp. 1-11.

See this record in the RMIT Research Repository at:

https://researchbank.rmit.edu.au/view/rmit:33431

Version: Accepted Manuscript

Copyright Statement: (C) 2015 IEEE

Link to Published Version:

http://dx.doi.org/10.1109/ICNSURV.2015.7121246 
This is the author pre-publication version. This paper does not include the changes arising from the revision, formatting and publishing process. The final version that should be used for referencing is:

A. Gardi, R. Sabatini, T. Kistan, Y. Lim and S. Ramasamy, "4 Dimensional Trajectory Functionalities for Air Traffic Management Systems", in proceedings of Integrated Communication, Navigation and Surveillance Conference (ICNS 2015), Herndon, VA, USA, 2015.

\title{
4 DIMENSIONAL TRAJECTORY FUNCTIONALITIES FOR AIR TRAFFIC MANAGEMENT SYSTEMS
}

\author{
Alessandro Gardi ${ }^{1}$, Roberto Sabatini ${ }^{l}$, Trevor Kistan ${ }^{1,2}$, Yixiang Lim $^{1,3}$ and Subramanian Ramasamy ${ }^{1}$ \\ ${ }^{1}$ RMIT University, Melbourne, Australia \\ ${ }^{2}$ THALES Australia, Melbourne, Australia \\ ${ }^{3}$ Imperial College London, London, UK
}

\begin{abstract}
The research presented in this paper focuses on the conceptual design of an innovative Air Traffic Management (ATM) system featuring automated 4Dimensional Trajectory (4DT) Planning, Negotiation and Validation (4-PNV) functionalities to enable Intent Based Operations (IBO). In order to meet the demanding requirements set by national and international organisations for the efficiency and environmental sustainability of air transport operations, a multi-objective 4DT optimization algorithm is introduced that represents the core element of the 4DT planning functionality. The 4PNV system interacts with airborne avionics also developed for 4DT-IBO such as the Next Generation Flight Management System (NG-FMS) on-board manned aircraft and Next Generation Mission Management System (NG-MMS) for Remotely Piloted Aircraft Systems (RPAS). In this article we focus on the 4-PNV algorithms, and specifically on the multi-objective 4DT optimization algorithm for strategic and tactical online operations. Simulation case studies are carried out to test the key system performance metrics such as 4DT computational time in online tactical Terminal Manoeuvring Area (TMA) operations.
\end{abstract}

\section{Introduction}

Large-scale aviation modernisation initiatives including the Next Generation Air Transportation System (NextGen) and Environmentally Responsible Aviation (ERA) programs in the US, and the Single European Sky Air Traffic Management Research (SESAR) and Clean Sky Joint Technology Initiative for Aeronautics and Air transport in Europe have been established to improve the operational efficiency, safety and environmental sustainability of aviation. As part of these and other national and international initiatives, a number of innovative operational and technological concepts have been identified for deployment in the civil aviation domain over the next decades [1-6]. The programmes prescribe the evolution of Air Traffic Management (ATM) into a highly automated, integrated and collaborative system, allowing a more predictable, flexible and efficient management of the airspace resources through higher levels of information sharing, automation and more accurate navigation. A number of technological enablers are required to introduce these innovations in the operational domain and to exploit their full potential. The foreseen evolutions will impact, in particular, the Communication, Navigation, Surveillance, ATM (CNS/ATM) and Avionics (CNS+A) systems context. In this perspective, the introduction of 4Dimensional Trajectories (4DT) in an Intent-BasedOperations (IBO) environment was identified as a key step to enhance the operational efficiency, costeffectiveness and environmental sustainability of aircraft operations.

\section{System Design}

New ground-based and airborne $\mathrm{CNS}+\mathrm{A}$ systems are required to assist the human ATM operators and flight crews in planning, reviewing and validating the most suitable 4DT intents in a timely manner, while exploiting the substantially increased levels of airspace, weather and traffic information that will be shared among all stakeholders. In this perspective, earlier studies addressed the development of automated ATM functionalities [717]. The CNS+A systems implement 4DT Planning, Negotiation and Validation (4-PNV) algorithms, datalink communications enhanced navigation and surveillance technologies, integrity monitoring and augmentation systems, as well as suitable interfaces/processing to enable automated negotiation and validation of the aircraft intents for greener air traffic operations. Some of the initial 4DT-IBO technologies start approaching the market already, while early stage advancements in the juridical framework are accommodating some levels of 
This is the author pre-publication version. This paper does not include the changes arising from the revision, formatting and publishing process. The final version that should be used for referencing is:

A. Gardi, R. Sabatini, T. Kistan, Y. Lim and S. Ramasamy, "4 Dimensional Trajectory Functionalities for Air Traffic Management Systems", in proceedings of Integrated Communication, Navigation and Surveillance Conference (ICNS 2015), Herndon, VA, USA, 2015.

enhanced operational capabilities. The research presented in this paper aims to develop an innovative 4-PNV ATM system that implements in a viable form the key operational and technological innovations identified by the major global aviation research initiatives. This paper expands the development of the ground-based 4-PNV system [1823], which is a substantially innovative evolution intended to introduce online 4DT management functionalities including a complete multi-objective 4DT optimization algorithm.

\section{Design Drivers}

The design of the new automated ground-based and airborne CNS+A systems is driven by a number of requirements, presented below.

- User-Preferred Trajectories: the systems shall enable aircraft to fly user-preferred optimal trajectories, as far as practicable from the airspace, weather and traffic perspectives. For this reason, a fundamental aspect is represented by negotiation and validation functionalities, whose effectiveness largely dictates how much of the original user intents can be accommodated.

- Operational Timeframes: a timeframe convention for this research was introduced in [20]. The research focuses in particular on the online context (i.e., when the flight mission is active), which is traditionally considered more technologically challenging as it poses strict requirements in terms of a timely and consistent identification of an adequate 4DT solution for each aircraft. Furthermore, the software systems and algorithms under development are conceived to improve the efficiency and sustainability of air traffic operations in presence of disruptions that could not be predicted in the offline context (i.e., before the beginning of the mission).

- Human Factors: the systems shall minimize the workload and maximize the situational awareness of the human operators, by limiting the intervention of flight crews and Air Traffic Control Operators (ATCO) to high added-value tasks such as higher-level decisionmaking, monitoring, supervision and emergency decisions.

- Resilience to Uncertainties: the systems shall exploit all the information that can be shared between the ground and the aircraft in order to maximize the predictability of future traffic states and react to the occurrence of unpredicted events in a timely manner, so to minimize their impacts. Moreover, the algorithms should stochastically assess the potential deviations to enable an expert selection of confidence levels and associated safety margins.

- 4DT Validation: the systems shall consistently identify solutions that fulfil the regulatory traffic separation criteria, the active airspace restrictions, and the aircraft performance limitations at all times. In particular, the computationally generated 4DT shall be assessed in terms of the lateral, vertical and longitudinal traffic separation criteria, airspace capacity and routing restrictions, as well as hazardous weather avoidance.

- Mixed Fleet/Mixed Equipage: the new CNS+A systems will be deployed gradually and progressively across the various Air Navigation Service Providers (ANSP) and aircraft fleets. Therefore, substantial levels of compatibility and interoperability with previous generation systems and procedures shall be entailed.

- Dense Traffic: the CNS+A systems shall consistently identify valid 4DT solutions even in the presence of dense air traffic severely limiting the feasible solution set.

- Multi-Capability: the systems shall be able to plan, negotiate and validate 4DT intents in all possible ATM instances.

- Global Air Traffic Optimality: the system should not attempt to accommodate the best 4DT intents of each aircraft individually, but instead perform an expert selection of the 4DT intents so to improve the overall optimality of air traffic in terms of the selected environmental and economic sustainability objectives. 
This is the author pre-publication version. This paper does not include the changes arising from the revision, formatting and publishing process. The final version that should be used for referencing is:

A. Gardi, R. Sabatini, T. Kistan, Y. Lim and S. Ramasamy, "4 Dimensional Trajectory Functionalities for Air Traffic Management Systems", in proceedings of Integrated Communication, Navigation and Surveillance Conference (ICNS 2015), Herndon, VA, USA, 2015.

- Offline Operations: most of the aforementioned objectives associated with online operations are effectively stricter than the equivalent ones for offline 4DT planning. Therefore, the planned extension of the 4-PNV system to offline operations will initially rely on the same model-set and algorithms used for online operations. Future research will assess the need for dedicated algorithms.

\section{System Architecture}

Fig. 1 depicts a schematic architecture of the 4PNV system.

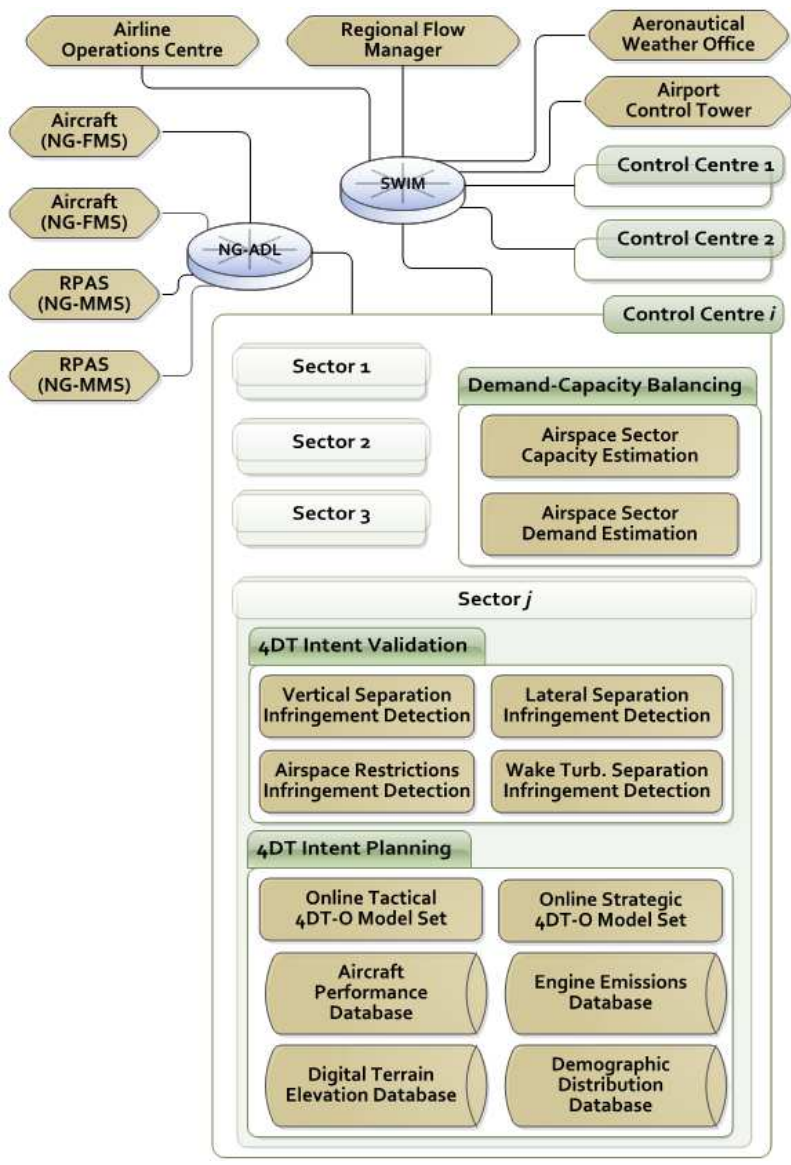

Figure 1. 4-PNV architecture

The online processes are distributed across the NG-FMS/NG-MMS, the Airline Operations Centres (AOC), the Air Navigation Service Providers (ANSP), the regional Air Traffic Flow Management (ATFM) centres and the ground-based ATM infrastructure. The ground-based ATM infrastructure is distributed among a number of Area Control Centres (ACC) and secondary facilities. Each centre/facility $i$ is typically tasked with the tactical control of a number of airspace sectors $j$, as well as some level of strategic flow management and airspace management duties. The 4-PNV is designed as a distributed and decentralized computational Decision Support System (DSS) deployed in each centre $i$ to assist the human operators while handling different strategic ATFM and tactical ATM roles.

\section{Trajectory Optimization}

A number of operational aspects and environmental impacts associated with the aircraft mission have significant dependencies on the flown trajectory. Trajectory optimization is, from an ATM perspective, the identification of the most suitable 3D/4D trajectory from the origin to the destination, based on dynamics/airspace constraints and user preferences, as well as meteorological and traffic conditions. Therefore, the adoption of computational algorithms for trajectory optimization represents a substantial evolution from the conventional flight planning methodologies currently in place and their associated limitations. From an operational perspective, since the offline flight plan is submitted as a substantially static entity, unforeseen weather and air traffic scenarios have the effect of progressively compromising its optimality. Another major limitation of conventional flight planning is due to the very narrow set of optimality criteria and their limited modelling, which do not encompass the full set of environmental impacts associated with aircraft operations. Currently, most of the noxious emission such as carbon monoxide (CO), nitrogen oxides $\left(\mathrm{NO}_{\mathrm{X}}\right)$ and unburnt hydrocarbons (UHC) are addressed by operational aircraft piloting recommendations, while the minimization of fuel consumption implicitly ensures a minimization of carbon dioxide $\left(\mathrm{CO}_{2}\right)$ emissions. Noise emissions are currently mitigated through a careful design and redesign of Area Navigation (RNAV) departure and arrival procedures. As this is a static approach in reducing the amount of perceived noise, it is subject to uncertainties associated with severe weather or traffic perturbations in the online context. Growing $R \& D$ efforts are therefore addressing practical implementations of noise models in novel airborne and ground-based CNS+A systems. As part of this research, customized algorithms are being developed 
This is the author pre-publication version. This paper does not include the changes arising from the revision, formatting and publishing process. The final version that should be used for referencing is:

A. Gardi, R. Sabatini, T. Kistan, Y. Lim and S. Ramasamy, "4 Dimensional Trajectory Functionalities for Air Traffic Management Systems", in proceedings of Integrated Communication, Navigation and Surveillance Conference (ICNS 2015), Herndon, VA, USA, 2015.

for the optimization of flight trajectories with respect to multiple objectives, while encompassing constraints that also entail strategic and tactical ATM and Air Traffic Flow Management (ATFM) directives as well as airspace The multi-objective optimisation suite comprises a number of models including the weather model, operational costs model, emissions model, airspace model, contrails model and noise model. The databases used in conjunction with the noise model are the demographic distribution and digital terrain elevation databases. The currently employed 4DT optimization algorithms are based on direct methods of the global orthogonal collocation category.

\section{Aircraft Dynamics}

The adopted three degrees of freedom (3DOF) point-mass dynamics model with variable mass is:

$$
\dot{\boldsymbol{x}}=\left\{\begin{aligned}
\dot{v} & =\frac{\tau \cdot T_{C L}-D}{m}-g \sin \gamma \\
\dot{\gamma} & =\frac{g}{v} \cdot(N \cos \mu-\cos \gamma) \\
\dot{\chi} & =\frac{g}{v} \cdot \frac{N \sin \mu}{\cos \gamma} \\
\dot{\phi} & =\frac{v \cos \gamma \sin \chi+v_{w_{\phi}}}{R_{E}+z} \\
\dot{\lambda} & =\frac{v \cos \gamma \cos \chi+v_{w_{\lambda}}}{\left(R_{E}+z\right) \cos \phi} \\
\dot{z} & =v \sin \gamma+v_{w_{z}} \\
\dot{m} & =-F F
\end{aligned}\right.
$$

Where $v$ is the true airspeed, $\boldsymbol{v}_{\boldsymbol{w}}$ is the wind velocity vector, $\gamma$ is the flight path angle, $\chi$ is the track angle, $m$ is the aircraft mass, $\phi \lambda$ and $z$ are respectively the geodetic latitude, longitude and altitude, $g$ is the gravity acceleration, $R_{E}$ is the geodetic Earth radius, $D$ is the aircraft drag, $T_{C L}$ is the maximum climb thrust. The control variables are $\boldsymbol{u}=\{N, \tau, \mu\}$, which respectively represent the load factor, the throttle and the bank angle. The drag is calculated with the conventional parabolic approximation as:

$$
D=\frac{1}{2} \rho v^{2} S C_{D 0}+\frac{2 C_{D 2} N^{2} m^{2} g^{2}}{\rho v^{2} S}
$$

Where $\rho$ is the local air density, and $S, C_{D 0}, C_{D 2}$ are obtained by the Eurocontrol's Base of Aircraft Data (BADA) database and respectively represend the aircraft reference area and the two parabolic drag coefficients. The drag coefficient increases to account for flaps and landing gear are also available [24]. Adopting the formulation from BADA, the maximum climb thrust and the fuel flow of a turbofan engine are calculated as [24]:

$$
\begin{gathered}
T_{C L}=C_{T 1} \cdot\left(1-\frac{H_{P}}{C_{T 2}}+C_{T 3} \cdot H_{P}^{2}\right) \cdot\left[1-C_{T 5} \cdot\right. \\
\left.\left(\Delta T-C_{T 4}\right)\right] \\
F F=\max \left[\begin{array}{c}
\tau \cdot C_{f 1} \cdot\left(1+\frac{v_{T A S}}{C_{f 2}}\right), \\
C_{f 3} \cdot\left(1-\frac{H_{P}}{C_{f 4}}\right)
\end{array}\right]
\end{gathered}
$$

Where $C_{T 1} \ldots C_{T 5}, C_{f 1} \ldots C_{f 4}$ are the thrust and fuel flow coefficients from the BADA empirical models [24]. The emission of a generic Gaseous Pollutant (GP) is modelled as:

$$
G P=\int_{t_{0}}^{t_{f}} E I_{G P} \cdot F F d t \quad[\mathrm{Kg}]
$$

The dependence of carbon monoxide (CO) and unburned hydrocarbon (HC) emission indexes on the throttle setting is empirically modelled as:

$$
E I_{C O / H C}=c_{1}+\exp \left(-c_{2} \tau+c_{3}\right)[\mathrm{g} / \mathrm{Kg}]
$$

Similarly, the nitrogen oxides $\left(\mathrm{NO}_{\mathrm{X}}\right)$ emission index is empirically modelled as:

$$
E I_{N O_{X}}=c_{1} \tau^{2}+c_{2} \tau+c_{3}[\mathrm{~g} / \mathrm{Kg}]
$$

Eq. 6 and 7 are developed to introduce an accurate nonlinear fit of the ICAO Emissions Databank [25], as detailed in [22]. The fitting parameters $c_{1,2,3}$ accounting for the $\mathrm{CO}$ emissions of 165 currently operated civil turbofan engines are $\boldsymbol{c}=\{0.556,10.21,4.068\} \quad$ for $\mathrm{CO}, \boldsymbol{c}=$ $\{0.083,13.2,1.967\}$ for $\mathrm{HC}$ and $c=\{7.32,17.07$, $3.53\}$ for $\mathrm{NO}_{\mathrm{X}}$. Linearized models can be introduced to enhance computational performance when required.

\section{Weather Model}

Diversions around unpredicted hazardous weather cells and extensive flight periods in regions of headwind or crosswind conditions have substantial negative effects on all environmental and economic performances of a flight, in addition to causing delays that perturb operations and negatively impact passenger satisfaction. Furthermore, many of the 
This is the author pre-publication version. This paper does not include the changes arising from the revision, formatting and publishing process. The final version that should be used for referencing is:

A. Gardi, R. Sabatini, T. Kistan, Y. Lim and S. Ramasamy, "4 Dimensional Trajectory Functionalities for Air Traffic Management Systems", in proceedings of Integrated Communication, Navigation and Surveillance Conference (ICNS 2015), Herndon, VA, USA, 2015.

models introduced in the trajectory optimization framework require accurate local atmospheric data as input. For all these reasons a suitable weather model is a fundamental component of trajectory optimization software frameworks. A macroscale model can provide the global distributions of pressure, temperature, winds aloft, and relative humidity, which are essential inputs for the contrail model. Higher resolution models working at smaller scales provide information about the cloud-base and visibility, the occurrence and dynamics of dangerous clouds, precipitations, fog and haze, clear air turbulence, wind shear and microbursts. The model currently employed processes the global weather data available from the National Climatic Data Center (NCDC) of the National Oceanic and Atmospheric Administration (NOAA), and selectively extrapolate the required information on a structured $4 \mathrm{D}$ grid. The data currently employed is extracted from the Global Forecast System (GFS), collected on a $0.25^{\circ}$ latitude and longitude resolution grid, updated every 6 hours (4 times daily), and including projection of up to 180hours in 3-hours intervals. Fig. 2 and Fig. 3 represent the results of the developed weather model for a 15hour advance forecast of wind, temperature and relative humidity 4D field sampled at 0600 UTC of April $3^{\text {rd }} 2015$.

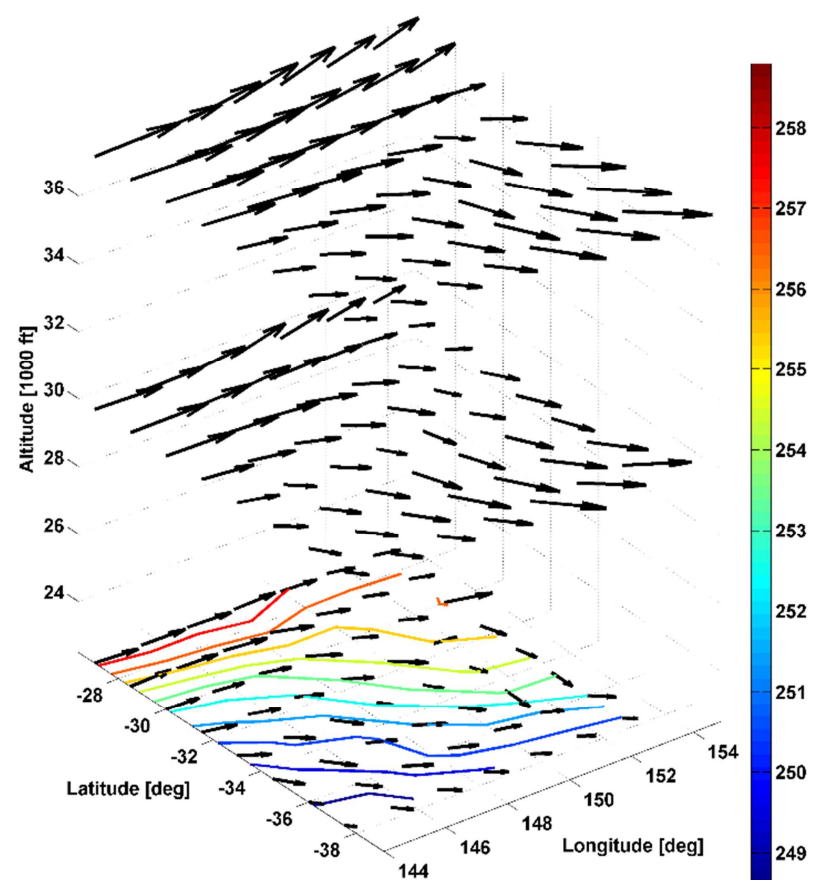

Figure 2. Wind and temperature 4D fields
Whenever interpolation is performed upon the original NCDC GFS data, the following expression (known as barometric formula) is adopted for the vertical trends:

$$
\frac{P}{P_{0}}=\left[\frac{\mathrm{T}_{0}}{\mathrm{~T}_{0}+L\left(h-h_{0}\right)}\right]^{\frac{g}{L \cdot R^{*}}}
$$

where $P$ is the extrapolated pressure, $P_{0}$ and $\mathrm{T}_{0}$ are reference pressure and temperature, $h$ and $h_{0}$ are the altitude of extrapolation and reference points, $L$ is the locally evaluated lapse rate and $R^{*}$ is the specific gas constant for air.

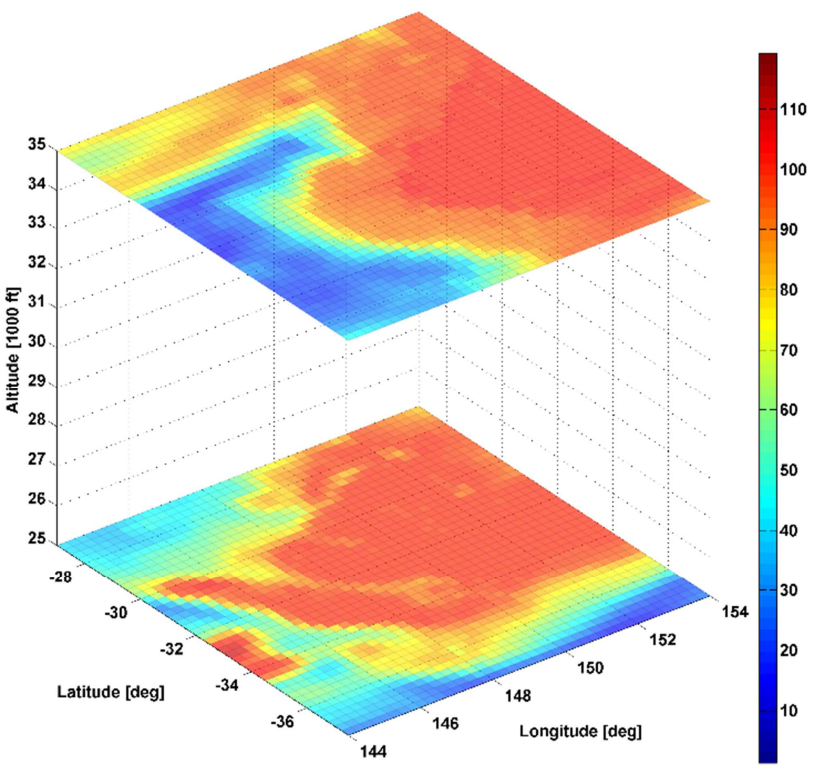

Figure 3. Relative Humidity 4D field

\section{Multi-Objective Optimality}

In line with the requirements for online tactical replanning, the weighted sum method, belonging to the category of a priori articulation of preferences, is adopted for the pre-identification of a combined performance index $J[20,26]$. The a priori multiobjective optimisation approach is conceptually represented in Fig. 4. The performance weightings can be dynamically modified along the flight and as part of an ongoing Collaborative Decision Making (CDM) process between the AOC and ANSP when required. Multiple optimal 4DT are generated on board each traffic, and then using a rule-based algorithm, a conflict free set of trajectories is found for all aircraft. 
This is the author pre-publication version. This paper does not include the changes arising from the revision, formatting and publishing process. The final version that should be used for referencing is:

A. Gardi, R. Sabatini, T. Kistan, Y. Lim and S. Ramasamy, "4 Dimensional Trajectory Functionalities for Air Traffic Management Systems", in proceedings of Integrated Communication, Navigation and Surveillance Conference (ICNS 2015), Herndon, VA, USA, 2015.

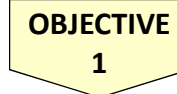

MULTI-OBJECTIVE OPTIMISATION

(A PRIORI ARTICULATION OF PREFERENCES)

COMBINED

OBJECTIVE

SINGLE-OBJECTIVE OPTIMAL CONTROL PROBLEM

DISCRETISATION AND INTEGRATION METHODS

\begin{tabular}{c} 
OPTIMAL \\
TRAJECTORY \\
\hline
\end{tabular}

Figure 4. Block diagram of multi-objective optimisation with a priori articulation of preferences [20]

\section{DT Optimisation Algorithm}

The numerical algorithm for the solution of the optimal control problem with respect of the combined objective resulting from the weighted sum a priori articulation of preferences is represented in Fig. 5. A mathematically optimal 4DT is generated by means of a numerical solver based on a direct method of the family of global orthogonal collocation (pseudospectral). This 4DT is a discretised version of a Continuous/Piecewise Smooth (CPWS) curve, which in general may not be flyable by human pilots nor by conventional Automatic Flight Control Systems (AFCS), as it includes transition manoeuvres involving multiple simultaneous variations in the control inputs. Moreover, the discretised CPWS consists of a very high number of overfly 4D waypoints, which would have unacceptable impacts on the Next-Generation Airborne Data-Link (NG.ADL) bandwidth usage. Therefore, a postprocessing stage is introduced, which employs manoeuvre identification algorithms to segment the trajectory in feasible flight legs, including straight and level flight, straight climbs and descents, level turns, and climbing/descending turns. The final result is a concisely described 4DT consisting of feasible flight segments.

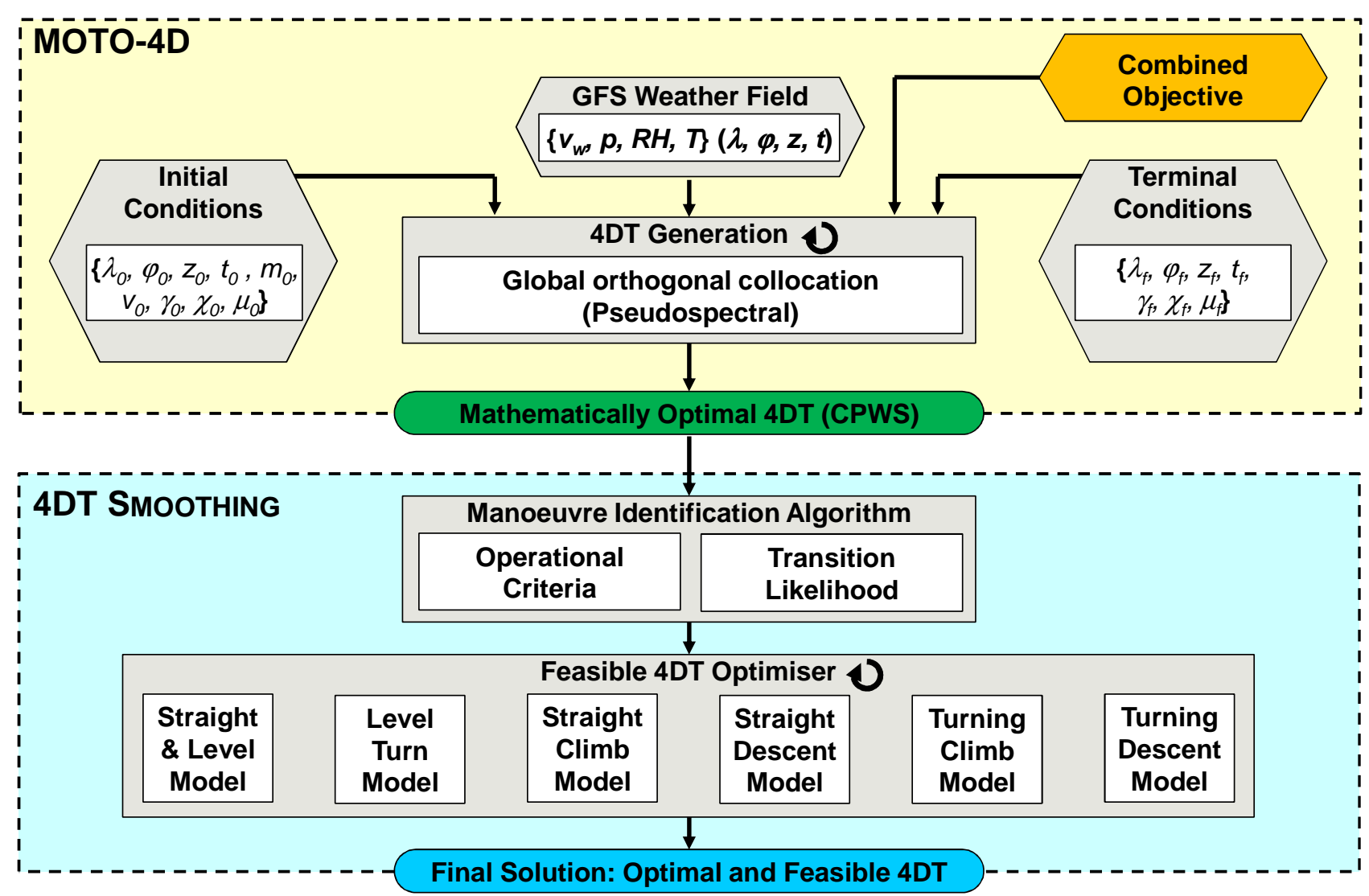

Figure 5. Block diagram of the 4DT optimisation algorithm 
This is the author pre-publication version. This paper does not include the changes arising from the revision, formatting and publishing process. The final version that should be used for referencing is:

A. Gardi, R. Sabatini, T. Kistan, Y. Lim and S. Ramasamy, "4 Dimensional Trajectory Functionalities for Air Traffic Management Systems", in proceedings of Integrated Communication, Navigation and Surveillance Conference (ICNS 2015), Herndon, VA, USA, 2015.

\section{Negotiation and Validation}

Negotiation and validation algorithms were developed to meet the stringent time requirements for strategic and tactical online operations. A singleattempt negotiation is required in order for the 4PNV to meet the online tactical rerouting requirements. In order to be adopted for both strategic online and tactical online contexts, with a reference time horizon of 3 minutes, it is required that the total duration of optimization, negotiation and validation processes must remain under 180 seconds. Our customized negotiation loops originally based on EUROCONTROL's DOC 97-70-14 [7] were introduced in [19] and are depicted in Fig. 6 and Fig. 7, which respectively represent the 4-PNV initiated and the NG-FMS initiated loops. The shared 4DT intents include the aircraft's unique identification and model, the wake-turbulence category, and the vector of 4DT segments. The 4-PNV system is the protagonist of the strategic online scenario as it retains a continuously updated global situational awareness. Unpredicted events prompt the 4-PNV to initiate a strategic replanning and negotiation by uplinking new constraints to the NG-FMS, triggering on-board 4DT optimization. Alternatively, the 4PNV may compute optimal 4DT and uplink them for validation by the aircraft. If, after on-board validation, constraint violations are detected (e.g. turn radius, climb rate), the aircraft downlinks a rejection message together with a new intent. Multiple negotiation loops are allowed in the strategic online scenario but minimized thanks to the availability of multiple intents for each aircraft. In the tactical online scenario, either the NG-FMS or the 4-PNV may initiate intent negotiations. The 4-PNV will act mainly as a key decision maker. The NG-FMS may initiate the negotiation due to locally detected weather changes, aircraft performance degradation, equipment failures or on-board emergency situations. Other manoeuvre-related factors such as inefficient heading changes, and unachievable climb/descent rates and altitudes due to the actual aircraft weight may also be causes of negotiation. In the tactical online scenario, a "single-loop" negotiation is ultimately sought due to the reduced time and stringent traffic management commitments.

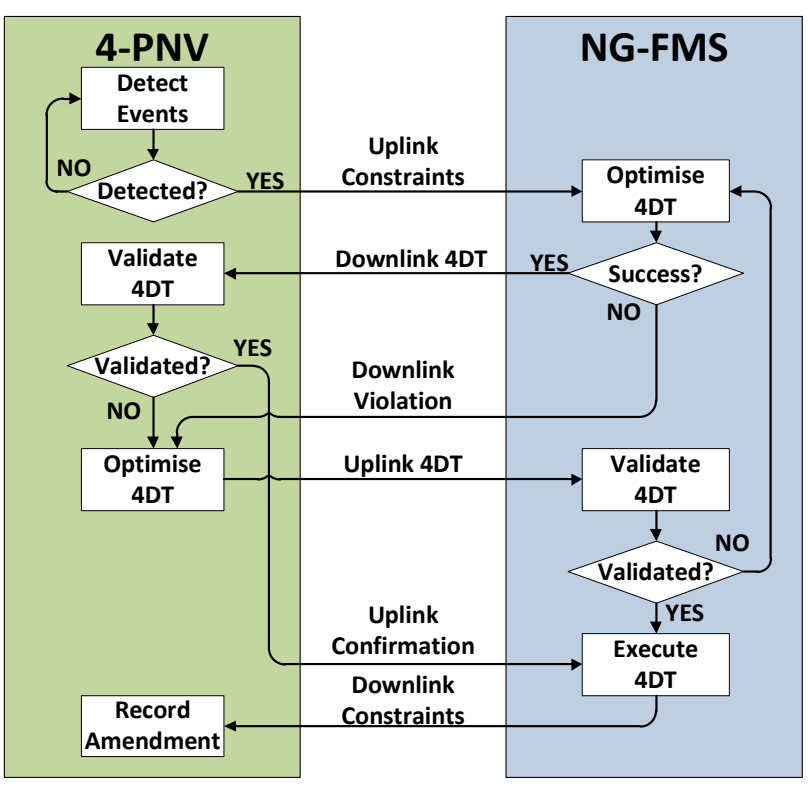

Figure 6. 4-PNV initiated 4DT Intent Negotiation/Validation Loop

4DT are checked for traffic conflicts and separation from hazardous phenomena. The validation algorithm assesses the lateral and vertical separation criteria and includes a simplified wake vortex modelling to assess the longitudinal separation.

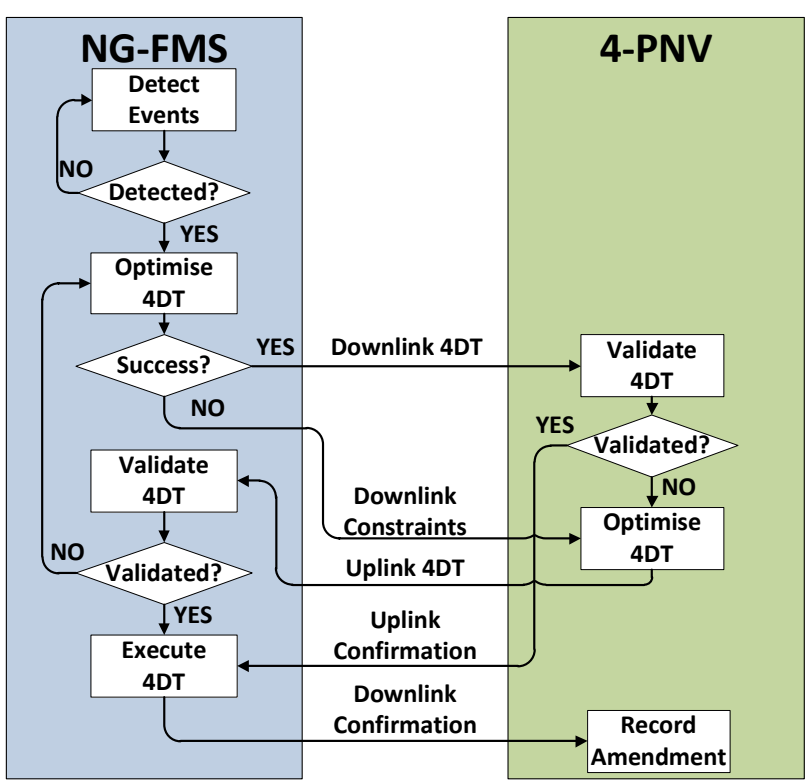

Figure 7. NG-FMS initiated 4DT Intent Negotiation/Validation Loop 
This is the author pre-publication version. This paper does not include the changes arising from the revision, formatting and publishing process. The final version that should be used for referencing is:

A. Gardi, R. Sabatini, T. Kistan, Y. Lim and S. Ramasamy, "4 Dimensional Trajectory Functionalities for Air Traffic Management Systems", in proceedings of Integrated Communication, Navigation and Surveillance Conference (ICNS 2015), Herndon, VA, USA, 2015.

\section{Air Traffic Flow Management}

Traditional ATM automation systems provide some level of support for implementing Air Traffic Flow Management (ATFM) measures, particularly during the tactical phase of operations. Emerging ATFM Decision Support Systems (DSS) provide additional capabilities, including:

- Common situational awareness, including display of weather, aeronautical messages, constraints, etc.

- Demand prediction based on scheduled, filed or live traffic data and/or analytical estimation/numerical simulations [27].

- Graphical representation of traffic (air situation display) and load (bar charts or similar).

- Fast-time simulation and "what-if" modelling of ATFM measures.

- CDM communication mechanisms (increasingly web-based).

- Compliance reporting and post-event analysis.

Major areas of research for ATFM DSS include Human Machine Interface and Interaction $\left(\mathrm{HMI}^{2}\right)$ techniques to visualise complexity and dynamic density concepts, merging metering with sequencing, i.e. the integration with Arrival and Departure Management (AMAN/DMAN) operations, and the development of regional ATFM concepts that support multiple ANSP. From the specific Demand-Capacity Balancing (DCB) measures listed above, it can be observed that ATFM addresses predominately demand-side issues; the ability to modify capacityside factors is currently limited to strategic and pretactical measures. This limitation is addressed by introducing Dynamic Airspace Management (DAM) functionalities. Both ATFM and DAM algorithms are currently being researched and evaluated within the 4-PNV system and in concurrent research activities [21].

\section{Simulation and Results}

The sequencing of dense arrival traffic towards a single final approach segment was extensively evaluated as a representative case study of online tactical Terminal Manoeuvring Area (TMA) operations [20]. The 4-PNV identifies the best arrival sequence among the available options. Longitudinal separation is enforced at the merge-point to ensure sufficient separation upon landing, and to prevent separation infringements in the approach phase itself. The 4-PNV is capable of performing point-merge at any metering point. After the initial intents have been stored in the 4-PNV, the point-merge sequencing algorithm allocates the available time slots accordingly. The assumed minimum longitudinal separation is 4 nautical miles on the approach path for medium category aircraft approaching at 140 knots, therefore the generated time slots are characterized by a 90 160 seconds separation depending on the wake-turbulence categories of two consecutive traffics. The results of one representative simulation run are depicted in Fig. 8. Fig. 9 depicts the computed 4DT in the AMAN schedule display format. Waypoints and lines depicted in magenta represent the flyable and concisely-described 4DT consisting of a limited number of fly-by and overfly 4D waypoints, obtained through the smoothing algorithm.

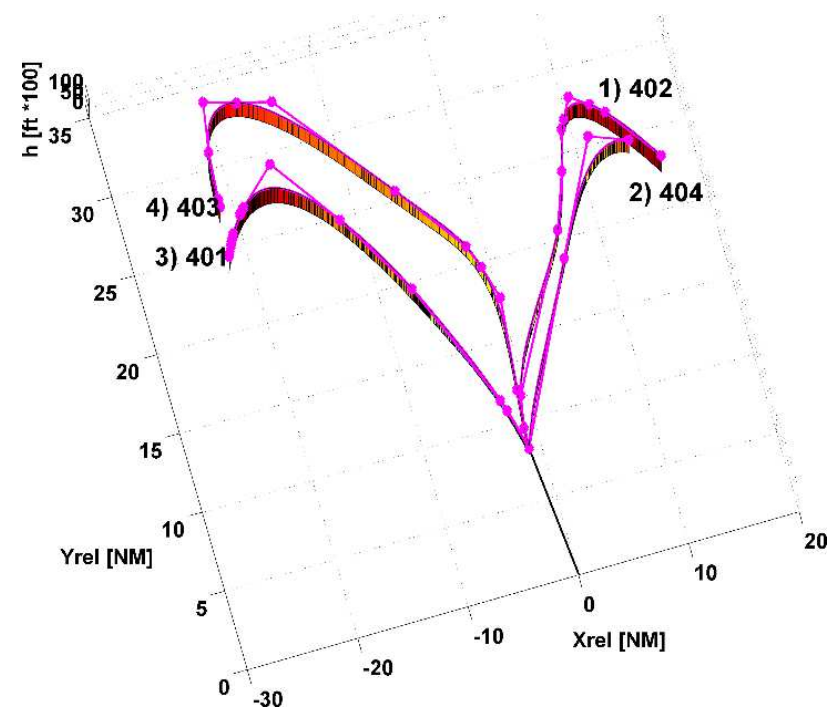

Figure 8. Results of the 4-PNV in the AMAN scenario

Monte Carlo simulation was performed, resulting in an average of 41 seconds for single newly generated 4DT intents, and consistently less than 60 seconds. The 4DT post-processing allowed to reduce discretised CPWS trajectories of 150 to 450 points into a number of fly-by and overfly 4D waypoints consistently below 20 . These results meet the set 
This is the author pre-publication version. This paper does not include the changes arising from the revision, formatting and publishing process. The final version that should be used for referencing is:

A. Gardi, R. Sabatini, T. Kistan, Y. Lim and S. Ramasamy, "4 Dimensional Trajectory Functionalities for Air Traffic Management Systems", in proceedings of Integrated Communication, Navigation and Surveillance Conference (ICNS 2015), Herndon, VA, USA, 2015.

design requirements for tactical online data-link negotiation of the 4DT.

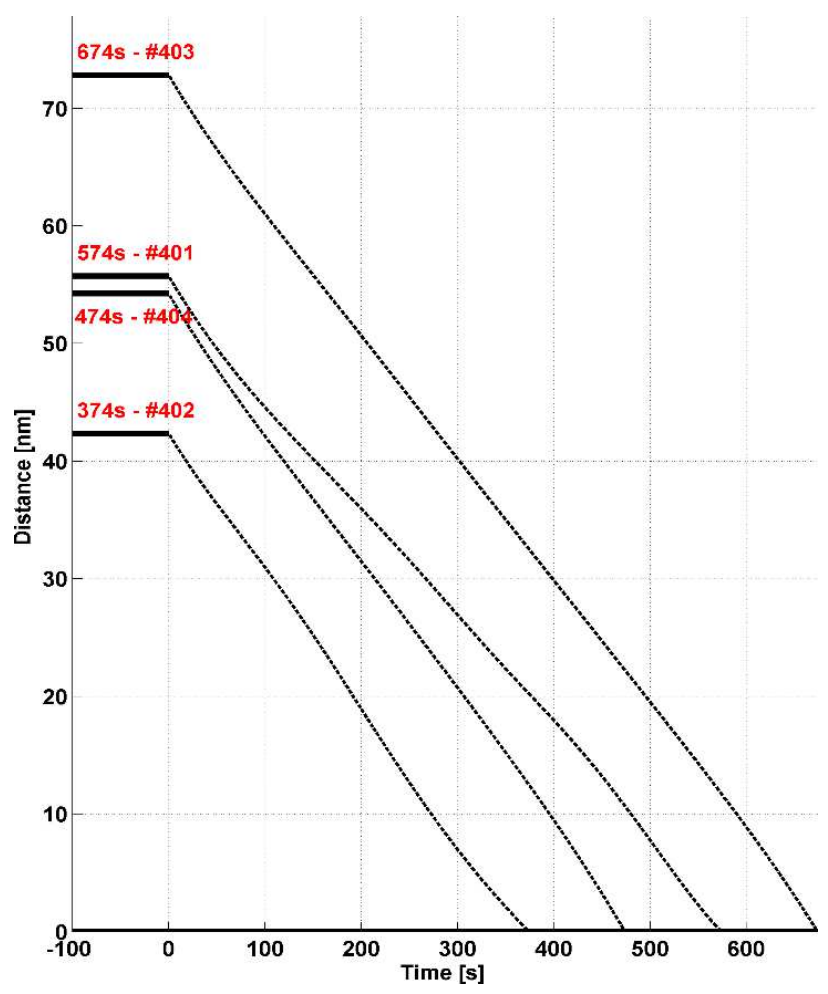

Figure 9. AMAN Schedule plot of the resulting 4DT

\section{Conclusions}

This paper presented the conceptual design of a novel 4-Dimensional Trajectory (4DT) Planning, Negotiation and Validation (4-PNV) system, conceived to introduce automated Air Traffic Management (ATM) functionalities in strategic and tactical online operations. The 4-PNV system is intended to operationally enable 4DT Intent Based Operations (IBO) in synergy with the Next Generation Flight Management System (NG-FMS) on board manned aircraft and Mission Management Systems (NG-MMS) for Remotely Piloted Aircraft Systems (RPAS). Simulation case studies allowed a preliminary assessment of the 4-PNV negotiation and validation models. In high air traffic density conditions, the complete process of NG-FMS/MMS 4DT intent generation, downlink to the 4-PNV and negotiation/validation is performed in less than 180 seconds. These results meet the 3 minutes timeframe assumed for online tactical routing/rerouting tasks and make the approach feasible for the intended applications. Future research will address the implementation and evaluation of other indirect and hybrid trajectory optimization methods, as well as enhanced algorithms for conflict detection. The concurrent research on safety-critical obstacle avoidance and Detect-and-Avoid (DAA) systems will be highly instrumental in the implementation and assessment of efficient optimization models for 4DT planning [28-32]. Reduced separation minima will be implemented to exploit the full potential of highaccuracy advanced Navigation and Guidance Systems (NGS) [33-36]. The 4-PNV evolutions will also incorporate various $\mathrm{CNS}+\mathrm{A}$ integrity monitoring and augmentation strategies currently being researched [37-40].

\section{References}

[1] "Concepts and Systems Integration Branch", NextGen Integration and Evaluation Capability, Multi-Year Program Plan ANG-E14, 2012.

[2] "European ATM Master Plan - The Roadmap for Sustainable Air Traffic Management", E.-S. JU, Ed., 2nd ed. Brussels, Belgium, 2012.

[3] "JPDO Trajectory-Based Operations (TBO) Study Team Report", NextGen Joint Planning and Development Office, 2011.

[4] D. Nakamura, S. van Trees, and F. Alexander, "JPDO TBO Summit - NextGen Avionics Roadmap and TBO JPDO Aircraft Working Group", ed. NextGen Joint Planning and Development Office, 2009.

[5] "The ATM Target Concept - D3", S. Consortium, Ed., ed: SESAR Definition Phase, 2007.

[6] H. Erzberger, "Transforming the NAS: The Next Generation Air Traffic Control System", NASA Ames Research Center NASA/TP-2004-212801, Moffett Field, CA, USA, 2004.

[7] I. A. B. Wilson, "Trajectory Negotiation in a Multi-sector Environment", Programme for Harmonised Air Traffic Management Research in EUROCONTROL (PHARE), Bruxelles, Belgium, 1998.

[8] J. E. Robinson III and D. R. Isaacson, "A concurrent sequencing and deconfliction algorithm for terminal area air traffic control", in proceedings of AIAA Guidance, Navigation and Control Conference 2000 (GNC 2000), Denver, CO, USA, 2000. DOI: $10.2514 / 6.2000-4473$ 
This is the author pre-publication version. This paper does not include the changes arising from the revision, formatting and publishing process. The final version that should be used for referencing is:

A. Gardi, R. Sabatini, T. Kistan, Y. Lim and S. Ramasamy, "4 Dimensional Trajectory Functionalities for Air Traffic Management Systems", in proceedings of Integrated Communication, Navigation and Surveillance Conference (ICNS 2015), Herndon, VA, USA, 2015.

[9] H. Erzberger, "The automated airspace concept", in proceedings of 4th USA/Europe Air Traffic Management Research and Development Seminar (ATM2001), Santa Fe, NM, USA, 2001

[10] A. P. Saraf and G. L. Slater, "An efficient combinatorial optimization algorithm for optimal scheduling of aircraft arrivals at congested airports", in proceedings of IEEE Aerospace Conference 2006 (AC 2006), Big Sky, MT, USA, 2006. DOI: 10.1109/AERO.2006.1655877

[11] E. Mueller, "Experimental Evaluation of an Integrated Datalink and Automation-Based Strategic Trajectory Concept", in proceedings of AIAA Aviation Technology, Integration and Operations conference 2007 (ATIO2007), Belfast, Northern Ireland, 2007. DOI: 10.2514/6.2007-7777

[12] E. Mueller and S. Lozito, "Flight deck procedural guidelines for datalink trajectory negotiation", in proceedings of 8th AIAA Aviation Technology, Integration and Operations Conference (ATIO 2008), Anchorage, AK, 2008. DOI: 10.2514/6.2008-8901

[13] H. Erzberger, T. A. Lauderdale, and Y. C. Chu, "Automated conflict resolution, arrival management and weather avoidance for ATM", in proceedings of 27th Congress of the International Council of the Aeronautical Sciences 2010, ICAS 2010, Nice, 2010, pp. 4210-4229

[14] M. A. Azzopardi and J. F. Whidborne, "Computational air traffic management", in proceedings, Seattle, WA, 2011, pp. 1B61-1B622. DOI: 10.1109/DASC.2011.6095967

[15] H. Erzberger, T. A. Lauderdale, and Y. C. Chu, "Automated conflict resolution, arrival management, and weather avoidance for air traffic management", Proceedings of the Institution of Mechanical Engineers, Part G: Journal of Aerospace Engineering, vol. 226, pp. 930-949, 2012. DOI: $10.1177 / 0954410011417347$

[16] T. A. Lauderdale and H. Erzberger, Automated separation assurance with weather and uncertainty, 3rd ENRI International Workshop on ATM/CNS, EIWAC 2013 vol. 290 LNEE, pp. 35-47, Springer Verlag, Tokyo, 2014. DOI: 10.1007/978-4-43154475-3_3

[17] T. Nikoleris, H. Erzberger, R. A. Paielli, and Y. C. Chu, "Autonomous system for air traffic control in terminal airspace", in proceedings of 14th AIAA
Aviation Technology, Integration, and Operations Conference (ATIO 2014), Atlanta, GA, USA, 2014

[18] A. Gardi, R. Sabatini, K. De Ridder, S. Ramasamy, D. Zammit Mangion, and L. RodriguezSalazar, "Automated Intent Negotiation and Validation System for 4-Dimensional Trajectory Based Operations", in proceedings of European Navigation Conference (ENC 2013), Vienna, Austria, 2013

[19] A. Gardi, R. Sabatini, S. Ramasamy, and K. de Ridder, "4-Dimensional Trajectory Negotiation and Validation System for the Next Generation Air Traffic Management", in proceedings of AIAA Guidance, Navigation, and Control Conference (GNC 2013), Boston, MA, USA, 2013. DOI: 10.2514/6.2013-4893

[20] A. Gardi, R. Sabatini, S. Ramasamy, and T. Kistan, "Real-Time Trajectory Optimisation Models for Next Generation Air Traffic Management Systems", Applied Mechanics and Materials, vol. 629, pp. 327-332, 2014. DOI: 10.4028/www.scientific.net/AMM.629.327

[21] R. Sabatini, A. Gardi, S. Ramasamy, T. Kistan, and M. Marino, "Novel ATM and Avionic Systems for Environmentally Sustainable Aviation", in proceedings of Practical Responses to Climate Change. Engineers Australia Convention 2014 (PRCC 2014), Melbourne, Australia, 2014. DOI: 10.13140/2.1.1938.0808

[22] A. Gardi, R. Sabatini, and S. Ramasamy, "Enabling 4-Dimensional Trajectory Based Operations of Manned and Unmanned Aircraft", in proceedings of 4th Australasian Conference on Unmanned Systems (ACUS 2014), Melbourne, Australia, 2014. DOI: 10.13140/2.1.2875.2968

[23] A. Gardi, R. Sabatini, S. Ramasamy, and M. Marino, "Automated ATM system for 4-dimensional trajectory based operations", in proceedings of 16th Australian International Aerospace Congress (AIAC16), Melbourne, Australia, 2015. DOI: $10.13140 / 2.1 .3635 .0244$

[24] Eurocontrol, "User Manual for the Base of Aircraft Data (BADA) Revision 3.11", Eurocontrol Experimental Centre (EEC) Technical/Scientific Report No. 13/04/16-01, Brétigny-sur-Orge, France, 2013.

[25] ICAO. ICAO AIRCRAFT ENGINE EMISSIONS DATABANK [Online]. Available: http://easa.europa.eu/node/15672 
This is the author pre-publication version. This paper does not include the changes arising from the revision, formatting and publishing process. The final version that should be used for referencing is:

A. Gardi, R. Sabatini, T. Kistan, Y. Lim and S. Ramasamy, "4 Dimensional Trajectory Functionalities for Air Traffic Management Systems", in proceedings of Integrated Communication, Navigation and Surveillance Conference (ICNS 2015), Herndon, VA, USA, 2015.

[26] R. T. Marler and J. S. Arora, "Survey of multiobjective optimization methods for engineering", Structural and Multidisciplinary Optimization, vol. 26, pp. 369-395, 2004. DOI: 10.1007/s00158-0030368-6

[27] P. U. Lee, C. Brasil, J. R. Homola, and T. Prevot, "Benefits and feasibility of the flexible airspace management concept: a human-in-the-loop evaluation of roles, procedures, and tools", in proceedings of 9th USA/Europe Air Traffic Management Research and Development Seminar (ATM2011), Berlin, Germany, 2011

[28] R. Sabatini, A. Gardi, and M. A. Richardson, "LIDAR Obstacle Warning and Avoidance System for Unmanned Aircraft", International Journal of Mechanical, Aerospace, Industrial and Mechatronics Engineering, vol. 8, pp. 62-73, 2014

[29] S. Ramasamy, R. Sabatini, and A. Gardi, "Avionics Sensor Fusion for Small Size Unmanned Aircraft Sense-and-Avoid", in proceedings of IEEE Metrology for Aerospace (MetroAeroSpace 2014), Benevento, Italy, $2014 . \quad$ DOI: 10.1109/MetroAeroSpace.2014.6865933

[30] R. Sabatini, A. Gardi, S. Ramasamy, and M. A. Richardson, "A Laser Obstacle Warning and Avoidance System for Manned and Unmanned Aircraft", in proceedings of IEEE Metrology for Aerospace (MetroAeroSpace 2014), Benevento, Italy, 2014, pp. 616-621. DOI: 10.1109/MetroAeroSpace.2014.6865998

[31] R. Sabatini, A. Gardi, and S. Ramasamy, "A Laser Obstacle Warning and Avoidance System for Unmanned Aircraft Sense-and-Avoid", Applied Mechanics and Materials, vol. 629, pp. 355-360, 2014.

DOI:

10.4028/www.scientific.net/AMM.629.355

[32] R. Sabatini, E. Roviaro, and M. Cottalasso, "Development of a Laser Collision Avoidance System for Helicopters: Obstacle Detection/Classification and Calculation of Alternative Flight Paths", in RTO-MP-092 Complementarity of Ladar and Radar, NATO Research and Technology Organization (RTO), 2002.

[33] R. Sabatini and G. B. Palmerini, Differential Global Positioning System (DGPS) for Flight Testing, RTO AGARDograph AG-160 Vol. 21, Flight Test Instrumentation Series, Systems Concepts and Integration Panel (SCI-135), NATO Science and Technology Organization, 2008.

[34] R. Sabatini, S. Ramasamy, A. Gardi, and L. Rodriguez Salazar, "Low-cost sensors data fusion for small size unmanned aerial vehicles navigation and guidance", International Journal of Unmanned Systems Engineering, vol. 1, pp. 16-47, 2013. DOI: 10.14323/ijuseng.2013.11

[35] R. Sabatini, S. Ramasamy, F. Cappello, and A. Gardi, "RPAS Navigation and Guidance Systems based on GNSS and other Low-Cost Sensors", in proceedings of 4th Australasian Conference on Unmanned Systems (ACUS 2014), Melbourne, Australia, 2014. DOI: 10.13140/2.1.3792.8008

[36] R. Sabatini, F. Cappello, S. Ramasamy, A. Gardi, and R. Clothier, "An innovative navigation and guidance system for small unmanned aircraft using low-cost sensors", Aircraft Engineering and Aerospace Technology, 2015

[37] R. Sabatini, T. Moore, and C. Hill, "Avionicsbased integrity augmentation system for mission- and safety-critical GNSS applications", in proceedings of 25th International Technical Meeting of the Satellite Division of the Institute of Navigation (ION GNSS 2012), Nashville, TN, 2012, pp. 743-763

[38] R. Sabatini, T. Moore, and C. Hill, "A new avionics-based GNSS integrity augmentation system: Part 1 - Fundamentals", Journal of Navigation, vol. 66, pp. 363-384, 2013. DOI: $10.1017 /$ S0373463313000027

[39] R. Sabatini, T. Moore, and C. Hill, "A new avionics-based GNSS integrity augmentation system: Part 2 - Integrity flags", Journal of Navigation, vol. 66, pp. 501-522, 2013. DOI: $10.1017 /$ S0373463313000143

[40] R. Sabatini, T. Moore, and C. Hill, "AvionicsBased GNSS Augmentation for Unmanned Aerial Systems Sense-and-Avoid", in proceedings of 26th International Technical Meeting of the Satellite Division of the Institute of Navigation (ION GNSS+ 2014), Tampa, FL, USA, 2014

\section{Integrated Communications Navigation and Surveillance (ICNS) Conference April 21-23, 2015}

